\title{
SCHOOL BULLYING: INTRODUCING THE ISSUE
}

Niti Rana*

\author{
I shall remember forever and will never forget \\ Monday: my money was taken. \\ Tuesday: names called. \\ Wednesday: my uniform torn. \\ Thursday: my body pouring with blood.
}

Friday: it's ended.

Saturday: freedom.

Abstract

Beginning of the world.

Void reigned then.

Darkness alone existed.

Then God created light.

Soon he created land,

rivers, hills and humans.

But he was not satisfied with this multitude. He

desperately wanted to carve the most beautiful

creature on the earth.

So at one fine heavenly moment, he set himself for the task. He then took all the lovely features from different creatures and lumped them into his new creation. "Abracadabra! Abracadabra!" chanted God, and lo! There emerged a camel.
The above lines were not taken from a story or a poem but rather from the final diary pages of thirteen year old Vijay Singh, who was found hanging from the banister rail at home on that particular Sunday (Coloroso, 2003). According to a report on Bullying Online (2004), there are no official statistics for the number of students being bullied at any one time or for the numbers who kill themselves due to distress over bullying, but it is believed that around sixteen students in the UK commit suicide every year as a result of bullying. The same report states that prolonged bullying could also lead to anxiety, low self-esteem, loss of appetite and extreme melancholy. According to Rigby, Smith and Pepler (2004), the most tragic outcome of peer victimization and school bullying is suicide. This makes the occurrence of school bullying assume an ominous nature.

An interesting fact is that although as per Watkins (2003) "bullying has existed as long as there has been human civilization" (9.2), it was not researchers, educational leaders, politicians, philosophers or social workers who first brought this issue to public attention but rather popular literature and authors who chose to unveil this issue through stories. For instance, there was much animated public discussion about bullying in English private schools in the mid $19^{\text {th }}$ century following the publication of the novel Tom Brown's School Days (Hughes, 1857). The book apparently "evoked strong expressions of abhorrence towards and condemnation of the practice of bullying and various suggestions were made on how it could be countered" (Rigby et al., 2004, p. 1) but nothing concrete 
resulted from all these suggestions. Interestingly, the time gap between the publication of this book and the first recorded research on school bullying is calculated to be more than a century long. In fact, the systematic examination of the nature and prevalence of school bullying only began with the work of Olweus in the 1970 s in Scandinavia, which meant that till the 1980 s there was very little research published on the subject of bullying. However, over the last two decades, bullying in schools has become an issue of widespread concern (Smith et al, 1999).

Watkins (2003) states that bullying is still considered by many to be part of a natural course of events or even an unchangeable part of human nature. However, research has revealed that bullying is a common and persistent problem in society, particularly in schools. Overall, a large number of children and youth experience some type of bullying during their educational experience. According to several researchers, bullying has been identified as a problem in many countries, including the United States, Canada, Japan, Australia, New Zealand, Germany, Belgium, Italy, Spain, Portugal, France, Switzerland, England, Ireland, and Finland and has taken a front seat in the research arena in many of these countries (Smith, et al., 1999).

As in any investigative effort, the two stumbling blocks which created some initial hurdles with regard to the study of this phenomenon were: (a) paucity of research interest till almost the end of the $20^{\text {th }}$ century, and (b) obstacles created by the ways in which researchers chose to define the phenomenon itself.

Searching for reasons for the lack of research activity in this area, Besag (1989) offers a plausible explanation:

Bullying in schools is one of the dark, hidden areas of social interaction which has thrived on a bed of secrecy and which has been neglected by professional investigation...The problem is covert, well hidden from the staff in school, buried in that curriculum organized by the pupils themselves (p. $\mathrm{x}$ ).

According to this author, the causes for the apparent lack of research, knowledge and concern about bullying can be attributed to its covert nature and occurrence without adult witness. Teachers only hear about it second-hand, if they are aware of it at all and parents are often the last to know. It would therefore appear that the problem is usually underestimated by adults.

It is reasonable to surmise that that one cause for the scarcity of research in Nepal could be that concerned professionals are insensitive to the problem and therefore carry out no research. This is consistent with Besag's (1989) statement that as long as there is little research, professionals will remain ill-informed. Generally speaking, it is possible that such a scenario could leave many children at risk. A further reason for the apparent lack of concern could be the assumption that only the victim suffers while teachers and the rest of the group remain unaffected. However, research indicates that it is not only the victims who suffer but also those who passively witness the attacks or threats tend to become anxious and distressed (Davies, 1986).

Another reason why this problem is not given due importance is the fact that age-old myths tend to surround the phenomenon of bullying. For example, according to Fuller and King (1995) some common school myths about bullying are: (a) bullying is part of human nature, it's always been there; (b) it's growth enhancing, kids need toughening up; (c) if one could only get rid of the bad kids; (d) teachers are already asked to do too much; (e) victims will usually tell me, I'm very approachable; and (f) it's society's problem, schools cannot be expected to solve everything (p. 8).

Research shows that many people engage in bullying behavior at some stage in their lives. However, according to the above report, it 
is whether these behaviors are accepted that will determine whether they continue. Some of the reasoned responses to the above myths are that getting rid of the perpetrators of these behaviors rarely works and usually prevents schools from looking at their own school culture and practices. Also, bullies generally operate overtly and covertly and use different tactics to minimize the awareness of most teachers who in turn consistently over-estimate the willingness of students to report bullying. What many teachers do not realize is that victims are usually afraid to tell a teacher for fear that it will only worsen the situation (ibid).

Besides the above myths, Besag (1989) states that in many cultures there is a traditional expectation that children will learn to look after themselves; that they will learn to cope and thus be better prepared for life. In addition to this, there may be a reluctance on the part of the school or local authority to admit to the problem of bullying because an admission could be read as incompetence and reflect badly on the school. According to a report by the UN Convention on the Rights of the Child (Taylor, 2000), there is often a "pressure on schools to paint a good picture of themselves in the marketplace" (p. 31). This indicates that a similar situation could be prevailing in Nepali schools as well.

At the same time, it is possible that adults are sometimes afraid to intervene because of fears that they might escalate the problem. However, as repeatedly stated by Besag (1989), school bullying is a problem which flourishes best on a bed of secrecy, hidden from those who could help. Therefore it seems that the exposure of the problem in itself may go a long way in understanding and possibly curtailing it.

The most obvious reason for the lack of information on bullying is that children themselves are reluctant to discuss the difficulties they face (Roberts \& Coursel, 1996). In addition, victims feel ashamed and degraded by the attacks and insults and consequently become incapable of admitting to this social failure. There was also a lack of parental pressure on professionals to address this problem which contributed to the lack of available expertise (Besag, 1989). These then were some of the reasons why researching the phenomenon of school bullying faced some initial delays.

As far as the second stumbling block, namely the problem in defining the phenomenon is concerned, it seems apparent that there was no agreement on any one definition of this phenomenon and researchers tended to look at the phenomenon emphasizing either one aspect of bullying or another. Most experts also agree that there still is considerable debate on a clear definition for the term 'bullying' (Boulton, 1997; Sutton, Smith \& Swettenham, 1999).

Researchers have defined the phenomenon encompassing varied aspects such as physical, behavioral, psychological and social. For example, one narrow definition involves physical harassment $(\mathrm{Ma}, 2001)$ although this probably would be the most common way of viewing acts of bullying. According to Hazler (1992), most adults and even some educators have indicated that verbal harassment should not be considered bullying and are not as severe as physical forms.

Some researchers use Olweus's (1986) definition, "a student is being bullied or victimized when he is exposed repeatedly and over time to negative actions on the part of one or more other students" (as cited in Olweus, 1993). This definition is in line with what is common in aggressive behavior and therefore stresses the behavioral aspect of bullying. According to this researcher, negative action is when someone intentionally inflicts injury or discomfort upon another (ibid). Many definitions thus categorize bullying as a subset of aggressive behavior that involves the intention to hurt another person (Olweus, 1978; Rivers \& Smith, 1994). On the other hand, Besag's (1989) definition of bullying "the repeated attack - physical, psychological, 
social or verbal - by those in a position of power, which is formally or situationally defined, on those who are powerless to resist, with the intention of causing distress for their own gain or gratification" (p. 4), while clarifying most of the components pertinent to this phenomenon, lays emphasis on psychological domination and power structures existing amongst individuals or groups. Similarly, Smith and Sharp's (1994) definition that bullying is a "systematic abuse of power," also implies an imbalance of power between the parties involved and incorporates the repetitive nature of bullying.

Other researchers have viewed the phenomenon of bullying from a slightly wider lens. For instance, Bjorkquist, Ekman and Lagerspetz (1982) note that bullying is "a special case of aggression which is social in nature" thereby implying that the phenomenon encompasses wider interactions involving society or community. Most recently, bullying has also been labeled as a form of terrorism in that it involves an unprovoked attack with the intention to cause harm to the victim (Ross, 2002).

It therefore seems that a lack of a common definition could lead to difficulties in studying the issue and drawing common conclusions, thus confirming Besag's (1989) statement that one of the difficulties in considering bullying is that this phenomenon "cannot be easily defined or measured" (p. x). Nevertheless, an amalgamation of the various definitions reveals that three factors are implicit in any bullying activity: (a) it must occur over a prolonged period of time rather than being a single aggressive act; (b) it must involve an imbalance of power, the powerful attacking the powerless; and (c) it can be verbal, physical or psychological in nature.

Notwithstanding the delay in research and the difficulty in agreeing to any one definition of bullying, researchers eventually began exploring this phenomenon in order to generate findings that would be beneficial to both school management and school children.
Investigating the chronology of research conducted in the area of school bullying shows that the main body of research originated in Scandinavia. Heinemann (1973) first drew attention to the problem after observing bullying in the playground on his routine visits to schools (as cited in Besag, 1989). His work aroused public interest and prepared the ground for the academic research of Olweus, which is apparently the largest in terms of size and complexity. As per Rigby (1996):

Not only was Olweus the first to recognize the evil of school bullying but, as a social scientist, he was able to examine its nature and incidence with care and precision as it occurred in both Swedish and Norwegian schools and was able to persuade the educational authorities in Norway of the importance of stopping bullying in schools and with their cooperation to mount a national campaign aimed at its systematic reduction. Two years later, evaluation studies showed that the incidence of bullying had been reduced in schools around Bergen by a remarkable 50\%. It was this sober, meticulous and scientifically designed intervention that encouraged educationalists in many other parts of the world to believe that something could indeed be done about school bullying (p. 12).

After being initially confined to the Scandinavian countries, the phenomenon of bullying among school children began to receive some public and research attention in other countries such as Japan, England, The Netherlands, Canada, USA and Australia in the late 1980s and early 1990s (Olweus, 1993). Most of these countries followed Scandinavia's example and conducted research to study the nature, extent and consequences of bullying. There was abundant interest in exploring the socio-environmental factors in the bullying phenomenon as well as the effectiveness 
of intervention programmes in order to combat the problem.

For example, when Australia began the systematic study of school bullying with the research work of Rigby and Slee (1989), a kind of detailed picture emerged of bullying in Australian schools upon which an understanding of peer victimization could be based (as cited in Rigby, 1996). Such research not only increased knowledge about the phenomenon but showed ways to deal with it. As per Rigby (1996), the research work undertaken in Australia was indebted to the team of researchers and counselors of the Sheffield Project in England who had carried out diligent research for several years not only on the incidence and effects of bullying in schools but also into methods of interventions which they developed and promoted to be used in schools in England.

According to White (1987), Japan was the only country outside Scandinavia to take an interest in studying bullying at a national level because education of children is a high national priority in Japan and any weakness in the system apparently causes an immediate alert. Researchers in Japan have tended to concentrate on a special concept of bullying known as 'shunning' which focuses on a particular victimizing process. Shunning represents the collective exclusion of an individual and is the typical type of Ijime in Japan (Tanaka, 2001). The occurrence of this form of bullying is based on the high regard for uniformity, homogeneity and order that exists in Japan (Fukaya, 1996). Thus any person who seems to be different and threatens the class culture subsequently becomes a target for bullying. This form of bullying is different from the typical bullying noted in the western countries where bullies actively attack a peer who is thought to be weaker.

As far as the United States is concerned, till the 1990s bullying was considered by many Americans as a normal occurrence; a "part of

$1 \quad$ Bullying (Japanese) growing up" (Smith \& Brain, 2000). However, at present, bullying is clearly a serious issue (Nansel, et al., 2001). According to research, bullying is considered the most predominant form of aggression and impacts the largest number of students when compared to other forms of violence (Ross, 2002). Still, some researchers are of the opinion that the United States could do a better job of addressing the issue and claim that this area of research is still largely neglected (Dupper \& Meyers-Adams, 2002).

From the above discussion, it is evident that several aspects of bullying have generated interest among researchers from different countries in the last two decades. The Scandinavian countries initiated research activity by studying the nature, extent and forms of bullying as well as the effectiveness of intervention programs with England and Australia following similar trends. Japanese researchers, on the other hand, focused on a typical form of bullying, namely shunning or collective ostracism of victims. Although bullying research in the United States has shown an inclination to study its relation to aggression and school violence, this country is still considered as lagging behind with regard to forming mandatory school level policies against bullying.

Despite the efforts of the trail blazing research conducted in some countries, it seems apparent that because bullying occurs mostly hidden from public or adult scrutiny it still tends to remain either as a taken-for-granted issue or a closeted one. The problem is exacerbated due to the fact that victims themselves often refuse to talk about it or share their fears and experiences. This helps to keep the problem underground and away from the gaze of those who could intervene and provide support to victims. The vicious cycle of victims being afraid to report cases of bullying, leading to bullies gaining confidence, resulting in more bullying taking place ultimately leads to a scenario where the phenomenon itself is not considered important enough to warrant serious 
research interest. This seems to still be the case as far as researching the school bullying issue in Nepal is concerned.

Nevertheless, in addition to the variety in research interest, it is clear that many researchers have realized the importance of studying this area and more countries are now placing the academic and practical investigation of school bullying high on the list of national and educational priorities. There are positive indications that the issue of school bullying has reached the highest administrative levels in terms of formulation of national level policies and intervention programs to combat the problem in several countries. In comparison to this surge of research activity in other countries, Nepal has yet to make a serious move to investigate this phenomenon. My research, The Experience of Being Victims of School Bullying: A Phenomenological Study (Rana, 2006) is therefore an attempt to cast the first stone into the still pond of school bullying research in Nepal.

\section{References}

Besag, V. E. (1989). Bullies and victims in schools. Buckingham: Open University Press.

Bjorkquist, K., Ekman, K., \& Lagerspetz, K. M. J. (1982). Bullies and victims: their ego picture, ideal ego picture and normative ego picture. Scandinavian Journal of Psychology, 23, 307-313.

Boulton, M. J. (1997). Teachers' views on bullying: Definitions, attitudes, and ability to cope. British Journal of Educational Psychology, 67, 223-233.

Bullying Online. www.bullying.co.uk/school/school_projects. htm Retrieved April 9, 2004.

Coloroso, B. (2003). The bully, the bullied, and the bystander. New York: HarperCollins.

Davies, G.T. (1986). A first year tutorial handbook. Oxford: Blackwell.

Dupper, D. R., \& Meyers-Adams, N. (2002). Low-level violence: a neglected aspect of school culture. Urban Education, 37(3), 350-364.

Fukaya, K. (1996). Children in 'ijime world'. Tokyo: KanekoShobo.
Fuller, A., \& King, V. (1995). Stop bullying! Melbourne: Mental Health Foundation of Victoria.

Hazler, R. I. (1992). What kids say about bullying. Executive Educator, 14, 20-22.

Hughes, T. (1989). Tom Brown's schooldays. New York: Oxford University Press. (Originally published 1857)

Ma, X. (2001). Bullying and being bullied: To what extent are bullies also victims? American Educational Research Journal, 38(2), 351-370.

Nansel, T. R., Overpeck, M., Pilla, R. S., Ruan, W. I., \& Simons-Morton, B. G. (2001). Bullying behavior among United States youth: Prevalence and association with psychosocial adjustment. Journal of the American Medical Association, 285, 20942100 .

Olweus, D. (1978). Aggression in schools: Bullies and whipping boys. Washington, DC: Hemisphere.

Olweus, D. (1993). Bullying at school: What we know and what we can do. Oxford: Blackwell Publishing.

Rana, N. (2006). The experience of being victims of school bullying: A phenomenological study. Unpublished doctoral thesis, Kathmandu University, Kathmandu.

Rigby, K. (1996). Bullying in schools: And what to do about it. London: Jessica Kingsley Publishers.

Rigby, K., Smith, P. K., \& Pepler, D. (2004). Working to prevent school bullying: Key issues. In P. K. Smith, D. Pepler, \& K. Rigby (Eds.), Bullying in schools: How successful can interventions be? Cambridge : Cambridge University Press.

Rivers, I., \& Smith, P.K. (1994). Types of bullying behavior and their correlates. Aggressive Behavior, 20, 359368.

Roberts, W. B. Jr., \& Coursel, D. H. (1996). Strategies for intervention with childhood and adolescent victims of bullying, teasing and intimidation in school settings. Elementary School Guidance and Counseling, 30, 204-212.

Ross, D. M. (2002). Bullying. In J. Sandoval (Ed.), Handbook of crisis counseling, intervention and prevention in schools (pp. 105-135). Mahwah, NJ: Erlbaum.

Smith, P. K., \& Brain, P. (2000). Bullying in schools: Lessons from two decades of research. Aggressive Behavior, 26, 1-9. 
Smith, P. K., Morita, Y., Junger-Tas, J., Olweus, D., Catalono, R., \& Slee. P. (Eds). (1999). The nature of school bullying: a cross national perspective. New York: Routledge.

Smith, P. K., \& Sharp, S. (Eds.) (1994). School bullying: Insights and perspectives. London: Routledge.

Sutton, J., Smith, P. K., \& Swettenham, J. (1999). Socially undesirable need not be incompetent: A response to Crick and Dodge. Social Development, 8(1), 132-134.

Tanaka, T. (2001). The identity formation of the victim of 'shunning'. School Psychology International, 22 (4), 463-477.
Taylor, A. S. (2000). UN convention on the rights of the child: Giving children a voice. In A. Lewis, \& G. Lindsay (Eds.), Researching children's perspectives. Buckingham: Open University Press.

Watkins, C. E. (2003). Protecting against bullies throughout the life cycle [Electronic version]. www. baltimorepsych.com/Bullying_Thru_Life_Cycle. htm Retrieved April 12, 2004.

White, M. (1987). The Japanese educational challenge. London: Free Press/Macmillan. 